\title{
C-banding and FISH in Chromosomes of the Blow Flies Chrysomya megacephala and Chrysomya putoria (Diptera, Calliphoridae)
}

\author{
Patricia P Parise-Maltempi ${ }^{+}$, Rita MP Avancini* \\ Departamento de Biologia Celular *Departamento de Parasitologia, Instituto de Biologia, Caixa Postal 6109,
Universidade Estadual de Campinas, 13083-970 Campinas, SP, Brasil
}

The blow flies Chrysomya putoria and $\mathrm{C}$. megacephala have $2 n=12$ chromosomes, five metacentric pairs of autosomes and an XX/XY sex chromosome pair. There are no substantial differences in the karyotype morphology of these two species, except for the $X$ chromosome which is subtelocentric in $\mathrm{C}$. megacephala and metacentric in C. putoria and is about 1.4 times longer in C. putoria. All autosomes were characterized by the presence of a $\mathrm{C}$ band in the pericentromeric region; $\mathrm{C}$. putoria also has an interstitial band in pair III. The sex chromosomes of both species were heterochromatic, except for a small region at the end of the long arm of the X chromosome. Ribosomal genes were detected in meiotic chromosomes by FISH and in both species the NOR was located on the sex chromosomes. These results confirm that $\mathrm{C}$. putoria was the species introduced into Brazil in 1970s, and not $\mathrm{C}$. chloropyga as formerly described.

Key words: Chrysomya - karyotype - NOR - heterochromatin - blow flies

Chrysomya megacephala and C. putoria belong to the family Calliphoridae which includes several common synanthropic forms, most of them with saprophagous habits. Some of these blow flies are considered a serious public health problem since certain species can cause myiasis in man and domestic animals (Greenberg 1971, 1973).

The original geographic distribution of these two species was $C$. putoria in Africa and $C$. megacephala in Asia and Australia (James 1970, Guimarães et al. 1978). At the end of the 1970s, $C$. putoria and C. megacephala were introduced into Brazil (Guimarães et al. 1974, Prado \& Guimarães 1982 ) and are currently very common and abundant species in this and other South American countries (Mariluis 1980, Laurence 1981, 1986, Prado \& Guimarães 1982).

Although considerable morphological variation has been found in the karyotypes of the species in this family, the chromosome number is very stable at $2 \mathrm{n}=12$ with five autosomes and a heteromorphic sex pair (Stevens 1908, Metz 1916, 1922, Keneuke 1924, Boyes \& Wilkes 1953, Boyes \& Van Brink 1965, Boyes \& Shewell 1975).

\footnotetext{
${ }^{+}$Corresponding author and recipient of a $\mathrm{PhD}$ studentship from Capes. Fax: +55-19-788-7821. Received 16 June 2000

Accepted 13 November 2000
}

Azeredo-Spin and Pavan (1983) studied the chromosomes of some Brazilian strains of three Chrysomya species a few years after their introduction into this country. Based on a comparison of their results with those of others (Üllerich 1976), these authors concluded that one of the species introduced into Brazil was $C$. chloropyga and not $C$. putoria. The external morphology of $C$. chloropyga is very similar to that of $C$. putoria. Based mainly on this similarity, Zumpt (1956) concluded that these flies were subspecies rather than species, although this author subsequently accepted them as separate species (Zumpt 1965). Boyes and Shewell (1975) and Üllerich (1976) also considered these flies to be distinct species based on a cytogenetic analysis.

In the present paper, we examined the karyotype of C. megacephala and C. putoria and confirmed that one of the species introduced into Brazil was in fact $C$. putoria. In addition, we identified the constitutive heterochromatic regions in the chromosomes of these species using C-banding and located the nucleolar organizer regions using in situ hybridization. The distribution of heterochromatin, the location of NORs and the absence or presence of sex chromosomes in different species of dipteran Muscoidea have been investigated, as has the modal karyotype number $(2 n=12)$ in this group, although species with $2 \mathrm{n}=10$ chromosomes have been described. In the latter cases, the absent pair is the sex pair (Boyes et al. 1964, Parise et al. 1996).

The two species studied here show somatic pairing. In all dipteran species and most cell types 
studied to date, there is intimate somatic pairing from early prophase up to metaphase (Metz 1916, Becker 1976).

\section{MATERIALS AND METHODS}

Flies - The colonies of C. megacephala and $C$. putoria were started from flies collected from putrid rat carcasses around the Institute of Biology at State University of Campinas. The species were identified by tenuous external morphological characteristics. The adults were kept in nylon cages $(30 \times 30 \times 48 \mathrm{~cm})$ at $24 \pm 2^{\circ} \mathrm{C}$ and $40-50 \%$ relative humidity on a $12 \mathrm{~h}$ light/dark cycle in the Entomology Laboratory of the Department of Parasitology. The adults had access to sugar cane $24 \mathrm{~h} /$ day and to ground beef a few hours/day. Water was always available.

Chromosome preparation - Mitotic chromosomes were obtained from the brains of L3 larvae. Sexing is not feasible in immature specimens of these species. Meiotic chromosomes were obtained from the testicular cells of young males. Hypotonic treatment and fixation were performed as described by Imai et al. (1988).

Chromosome morphology - For morphological studies, the slides were stained mainly with $10 \%$ Giemsa. Mean descriptive values of the karyotypes were calculated from the information obtained from a minimum of one well-spread mitotic metaphase plate from each of 5-10 individuals. The nomenclature of Levan et al. (1964) was used to describe the chromosome morphology.

C-banding - Sumner's technique (1972) was used with slight modification in the temperature to allow the localization of constitutive heterochromatic regions.

FISH - In situ hybridization was performed in meiotic cells using a $12 \mathrm{~kb}$ rDNA probe (pDm 238Drosophila melanogaster). Chromosome preparations were pretreated with RNAse, dehydrated in an ethanol series and air dried. The preparations were then denatured in $70 \%$ formamide solution (formamide in $20 \% 10 \mathrm{xSSC}$ ) at $70^{\circ} \mathrm{C}$ for $2 \mathrm{~min}$ and immediately dehydrated in cold ethanol. The hybridization was performed for at least $16 \mathrm{~h}$ in a humid chamber at $37^{\circ} \mathrm{C}$.

The slides were washed twice in $50 \%$ formamide solution (in 2xSSC), twice in $2 \mathrm{xSSC}$ for $5 \mathrm{~min}$ each and then incubated with the first antibody (antibiotin) in a humid chamber at $37^{\circ} \mathrm{C}$ for $45 \mathrm{~min}$. After washing in PBT (PBS 1x, 0.1\% Tween 20 and $0.4 \%$ BSA 30\%, w/v), the slides were incubated with the second antibody (RAGFITC) for $45 \mathrm{~min}$ in a humid chamber at $37^{\circ} \mathrm{C}$.

Following a final wash in PBT, the slides were stained with propidium iodide and mounted in antifading. The probe was labeled using a Bionik kit
(Gibco-nick translation) and denatured for $10 \mathrm{~min}$ at $100^{\circ} \mathrm{C}$ immediately before hybridization.

After in situ hybridization, some slides were washed in water for $2 \mathrm{~h}$ and stained with Giemsa for better morphological identification of each chromosome and to ascertain the exact location of the signal (Viegas-Pequignot 1992).

All slides were examined using an Olympus fluorescence microscope and photographed with 400 ASA color negative film.

\section{RESULTS}

The karyotypic complements of $C$. putoria (Figs 1-5) and C. megacephala (Figs 6, 7) consist of five autosomal pairs and one pair of sex chromosomes (females XX/males XY). All the chromosomes of both species are metacentric (Table), except for the $\mathrm{X}$ chromosome of $C$. megacephala which is subtelocentric. Analysis of the total chromosome length (TCL) show no major difference in karyotype length (C. megacephala, $36.8 \mathrm{~mm}$ and C. putoria, $37.8 \mu \mathrm{m})$.

The $\mathrm{X}$ chromosome of $C$. putoria is 1.4 times longer than that of $C$. megacephala and in both species the $\mathrm{Y}$ chromosome is much shorter than the $\mathrm{X}$ chromosome. One of the $\mathrm{X}$ chromosomes from female $C$. putoria shows a satellite at the end of the short arm, similar to that seen in male $\mathrm{X}$ chromosomes (Figs 1-4). In C. megacephala, some preparations also show a secondary constriction in the long arm of the X chromosome of Fig. 6.

All the autosomes of both species show a $C$ band in the pericentromeric region (Figs 3-7). A small interstitial band is also present in chromosome III of $C$. putoria and is probably related to a secondary constriction region (Fig. 5; arrow).

The X chromosomes of $C$. putoria are heterochromatic, except for a small region located at the end of the long arm (Figs 3, 4). A similar C-band pattern was seen in the $\mathrm{X}$ chromosome of $C$. megacephala which also has a terminal region that is not C-banded (Figs 6,7). The Y chromosome of both species is totally heterochromatic.

In situ hybridization shows that there is a NOR on the sex chromosomes of both species (Figs 8, 9). The sex chromosomes assumes an allocyclic behavior typical of heterochromatic chromosomes at meiosis (Figs 8, 9), and for this reason it was not possible to be certain whether the signal was located on the $\mathrm{X}$, or both sex chromosomes.

\section{DISCUSSION}

C. putoria is morphologically very similar to C. chloropyga. Based on the similarity of the male genitalia, Zumpt (1965) concluded that $C$. putoria was a variant of $C$. chloropyga which he classified as $C$. chloropyga form putoria. However, subse- 
quent crossing experiments showed that these flies were at least partly genetically isolated and merited species status (Zumpt 1975). Boyes and Shewell (1975) and Üllerich (1976) considered these species to be distinct based on their cytogenetic characteristics, and this is the currently accepted view.

Azeredo-Spin and Pavan (1983) considered the karyotypic organization of C. chloropyga to be more similar to that described by Üllerich (1976) for $C$. chloropyga than for $C$. putoria. However, there are very subtle differences between the karyotypes described by Üllerich (1976) for $C$. putoria and $C$. chloropyga. This author differentiated the two species on the basis of two features present only in C. putoria: an interstitial $\mathrm{C}$ band in chromosome III and a secondary constriction in the $\mathrm{Y}$ chromosome. An interstitial band was indeed ob- served in the population we studied but, in agreement with Azeredo-Spin and Pavan (1983), no constriction was seen in the Y chromosome.

Our data on chromosomal morphology differed from those of Üllerich (1976) only for pair II, which he considered submetacentric in C. putoria and $C$. chloropyga, although no arm ratios were reported.

The gross morphology observed here was more similar to that reported by Boyes and Shewell (1975) for a population from Johannesburg, in which all the autosomes were metacentric, than to that of other authors (Üllerich 1976, Azeredo-Spin \& Pavan 1983).

Secondary constrictions were found only in chromosome III. Boyes and Shewell (1975) reported no such constriction, whereas Üllerich (1976) observed secondary constrictions in chromosomes II and III of both $C$. putoria and $C$.

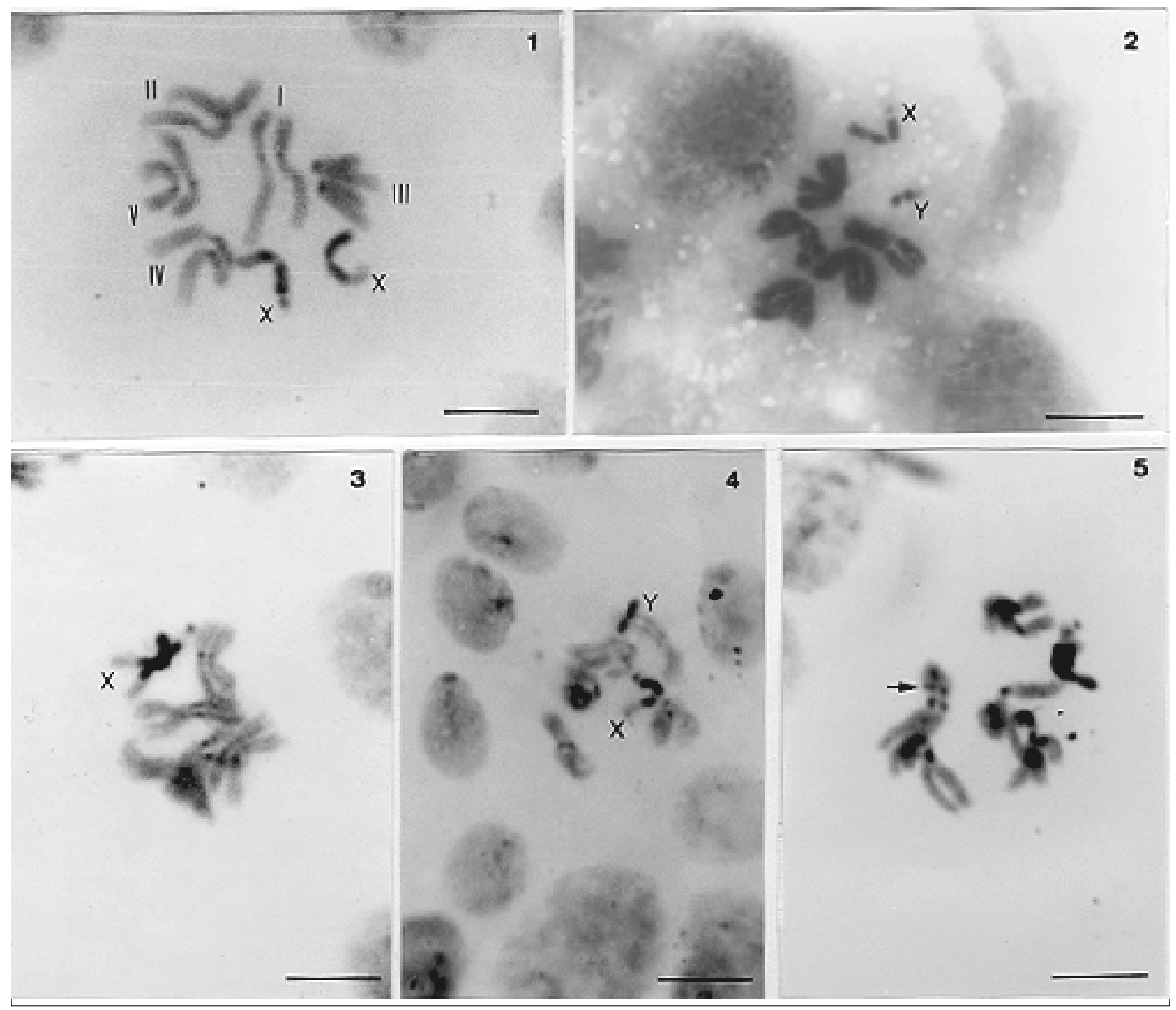

Mitotic chromosomes of Chrysomya putoria. Fig. 1: female C banded metaphase showing 12 chromosomes. Fig. 2: male metaphase. Figs 3-5: C-banded chromosomes. Note the banded pericentromeric regions. In Fig. 3 the X chromosomes show a terminal $\mathrm{C}$ band negative region. In Fig. 4 the $\mathrm{Y}$ is totally heterochromatic and in Fig. 5 there is an interstitial band in pair III. Scale bar $=10 \mu \mathrm{m}$ 


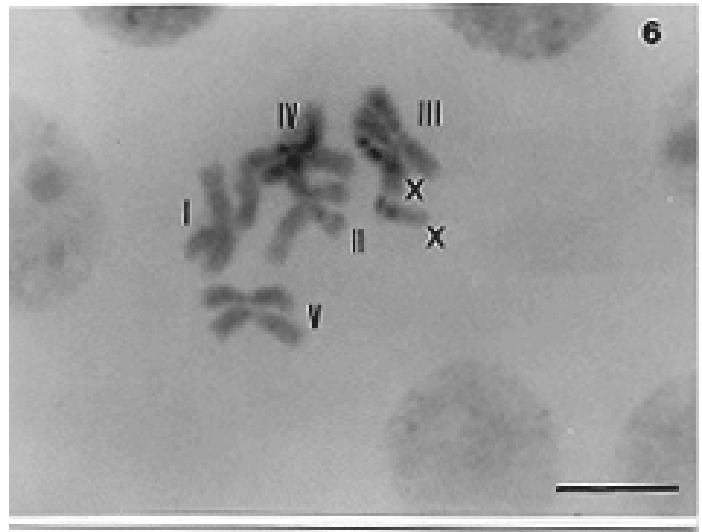

7

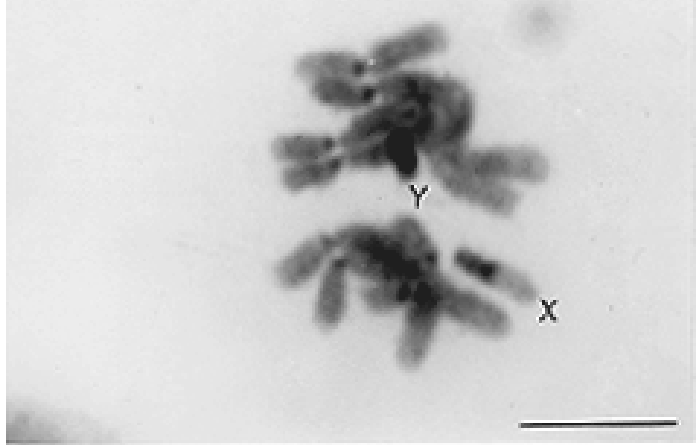

C-banded mitotic chromosomes of Chrysomya megacephala. Fig. 6: female chromosomes. Fig. 7: male chromosomes. The autosomes exhibit somatic pairing. The $\mathrm{Y}$ chromosome is totally heterochromatic and the $\mathrm{X}$ chromosome is partially heterochromatic. Scale bar $=10 \mu \mathrm{m}$

chloropyga. Azeredo-Spin and Pavan (1983) reported one secondary constriction on chromosome III and possibly one on chromosome II. In addition to chromosome III, we also observed a secondary constriction in the $\mathrm{X}$ chromosomes.

The C-banding pattern of $C$. putoria observed here was very similar to that described by Üllerich (1976), with pericentromeric bands in all autosomes, interstitial bands in chromosome III and totally heterocromatic $\mathrm{Y}$ and $\mathrm{X}$ chromosomes, except for a distal part of the long arm of the latter.
Thus, comparison of our data on chromosomal morphology with those of Boyes and Shewell (1975) and Üllerich (1976) and with the C-banding pattern provided by Üllerich (1976), together with more recent studies, indicated that the species introduced into Brazil was $C$. putoria.

The autosome lengths observed for $C$. megacephala were very similar to those found by Azeredo-Spin and Pavan (1983) for populations from the same region (Campinas, Brazil). However, the latter authors found a secondary constriction in pairs I, III and IV (VI, IV and III, respectively, of these authors' classification) which was not observed here. C. megacephala from Japan also shows a secondary constriction in pair III (Üllerich 1963). Boyes and Shewell (1975) found no such constriction in populations from Australia. In the present study, a secondary constriction was seen in the $\mathrm{X}$ chromosome, although Azeredo-Spin and Pavan (1983) and Üllerich (1963) reported no such structure. In our specimens, this chromosome was subtelocentric, which agree with the above authors. In strains from Australia, the $\mathrm{X}$ chromosome is telocentric, with a secondary constriction. The divergence between these two Brazilian populations most likely appeared after the introduction and establishment of C. megacephala in this country.

Among the Calliphoridae studied to date, including most Chrysomya species, the sex chromosomes are medium length, heterochromatic chromosomes, and sex is probably controlled by a determinant male factor present in the $\mathrm{Y}$ chromosome (Üllerich 1963, 1976, Bedo 1991). Variations in sex chromosome size were reported by Boyes and Shewell (1975) for C. putoria and we also observed variations in the occurrence of a secondary constriction in X chromosomes. Variations in this chromosome were described by Üllerich $(1961,1963$, 1971, 1973, 1976), whereas Melander (1963) described some Calliphoridae species in which the sex chromosomes were not morphologically differentiated $(\mathrm{XX} / \mathrm{XY})$. Indeed, the smallest chromosome pair in species such as $C$. albiceps and $C$. rufifacies are not the sex chromosomes. Üllerich $(1973,1976)$ believed that the sex chromosomes

TABLE

Analysis of the somatic complements of Chrysomya megacephala and C. putoria

\begin{tabular}{lcccccccccccccc}
\hline \multicolumn{1}{c}{ C. megacephala } & \multicolumn{1}{c}{ C. putoria } \\
\hline Chromosomes & I & II & III & IV & V & X & Y & I & II & III & IV & V & X & Y \\
Length $(\mu \mathrm{m})$ & 7.5 & 7.1 & 6.2 & 6.1 & 5.5 & 4.4 & 2.5 & 7.5 & 6.8 & 6.3 & 5.7 & 5.4 & 6.1 & 1.8 \\
Arm ratio & 1.3 & 1.3 & 1.4 & 1.4 & 1.3 & 4.1 & 1.4 & 1.3 & 1.2 & 1.2 & 1.5 & 1.2 & 1.2 & 1.0 \\
Relative length & 0.20 & 0.19 & 0.17 & 0.16 & 0.15 & 0.13 & 0.07 & 0.20 & 0.18 & 0.17 & 0.15 & 0.14 & 0.16 & 0.05 \\
Designation & M & M & M & M & M & St & M & M & M & M & M & M & M & M \\
\hline
\end{tabular}

M: metacentric; St: subtelocentric. The relative length of $\mathrm{Y}$ was expressed as a function of the length of $\mathrm{X}$. 
had been lost in C. rufifacies and that sex was determined by another pair of chromosomes. In contrast, Boyes and Shewell (1975) stated that the small heterochromatic pair in $C$. rufifacies populations corresponded to the sex chromosomes.

In many insects, including the higher Diptera, secondary constrictions and NORs are located together on heterochromatic sex chromosomes (Hadjiolov 1985). Üllerich (1963) described the karyotype of Lucilia cuprina and showed that the nucleolus was associated with secondary constrictions present in the $\mathrm{X}$ and $\mathrm{Y}$ chromosomes. Through in situ hybridization, Bedo (1992) detected a positive signal for rDNA in both sex chromosomes of L. cuprina and C. bezziana, and both regions were associated with the secondary con- strictions. Similarly, in the present study, in situ hybridization located NORs in the sex chromosomes of C. putoria and C. megacephala. However, since these chromosomes assume an allocyclic behavior in meiosis, it was not possible to determine whether the signal was located on the $\mathrm{X}$ or both $\mathrm{X}$ and $\mathrm{Y}$ chromosomes. This variation in the behavior of the sex chromosomes has also been described for species of Tachinidae (Manjunatha \& Puttaraju 1997). The latter authors indicated that the sex chromosomes had a strong association of short duration and, like the species studied here, the $\mathrm{X}$ chromosome abutted the $\mathrm{Y}$ chromosome at metaphase. This behavior suggested that the repetitive DNA sequence, which could recognize a specific protein conformation
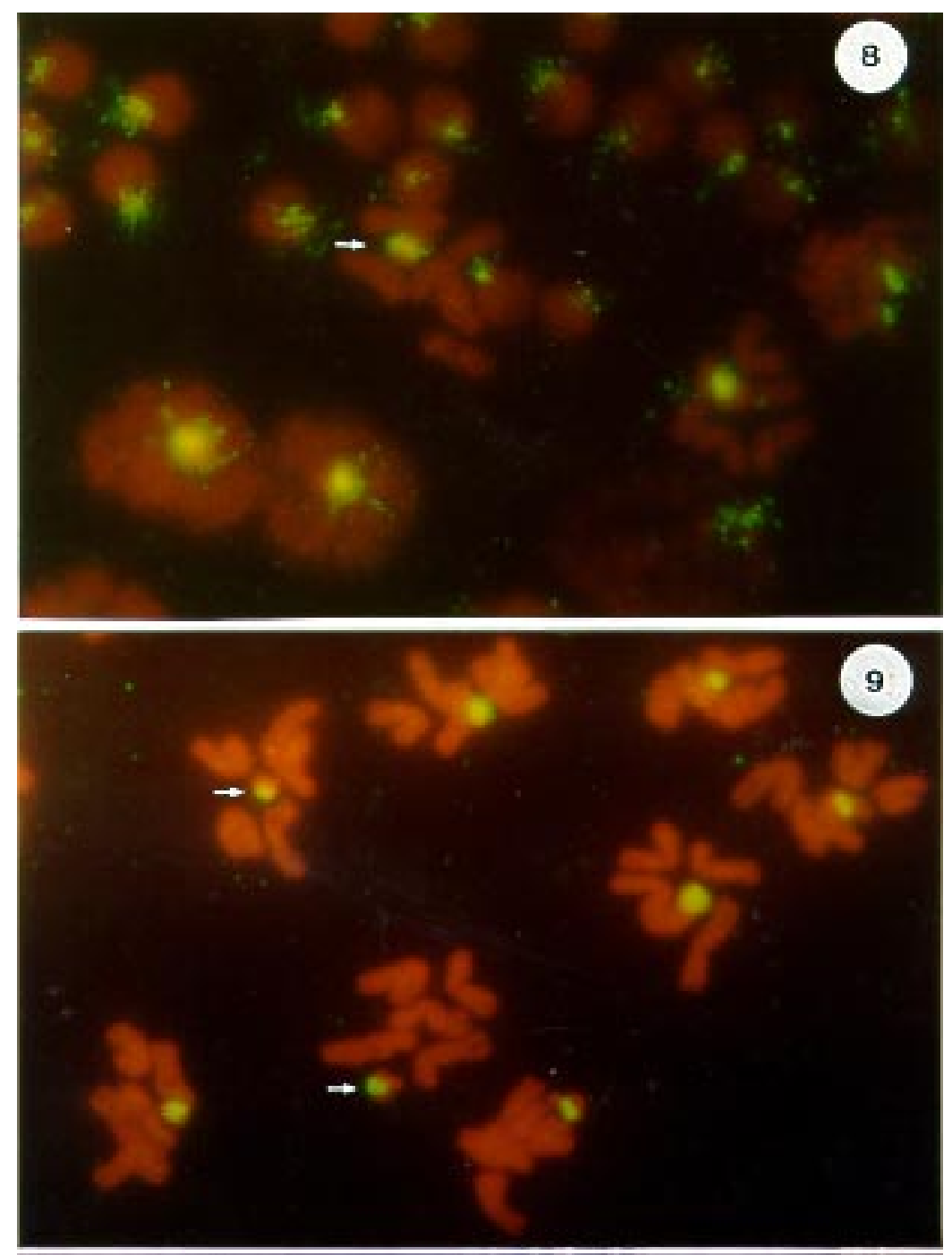

Fig. 8: FISH in Chrysomya putoria meiotic chromosomes. Fig. 9: FISH in C. megacephala meiotic chromosomes. The white arrows indicate the FISH signal in the sex chromosomes; the hybridization signal is yellow. The chromosomes and nuclei were counterstained with propidium iodide (red). 
might exist on some part or the whole length of the arms of the $\mathrm{X}$ or $\mathrm{Y}$ chromosomes and that this could be important in maintaining their association (Comings \& Riggs 1971).

NORs are not always located on the sex chromosomes. For instance, in C. rufifacies the NOR is located on the small heterochromatic pair VI. In some Muscidae species, NORs occur on autosomes, even in species with sex chromosomes (Parise-Maltempi \& Avancini, unpublished data). In species such as $C$. rufifacies, the factors involved in sex determination may be located on another chromosome.

Comparison of the karyotype, C-banding pattern and sex chromosomes shows that $C$. megacephala and $C$. putoria are very similar, as would be expected for species of the same genus. In contrast, $C$. rufifacies, which belongs to the same genus, showed a basic difference in that the NOR was located on an autosome.

Foster et al. (1980) stated that the linkage groups of Musca domestica (Hiroyoshi 1977) and, possibly, Drosophila (Sturtevant \& Novitski 1941) may be homologous with L. cuprina. This raises the possibility that the linkage groups of the higher Diptera may have been conserved largely intact. The similarity in the karyotypes of the muscoid calyptrate Diptera, which have five autosomal pairs (Boyes 1967), is consistent with this hypothesis (Foster et al. 1980).

\section{ACKNOWLEDGMENTS}

To Dr SM Recco-Pimentel for use of the fluorescence photomicroscope and some of her laboratory facilities, Dr AP Prado for his valuable information on the taxonomy and distribution of Calliphoridae and Dr LM Botella (Centro de Investigaciones Biológicas, Madrid, Spain), for supplying the pDm, Dr Stephen Hyslop (Department of Pharmacology-Unicamp) for reviewing the English of the manuscript.

\section{REFERENCES}

Azeredo-Spin AML, Pavan C 1983. Karyotypes and possible regions of origin of three species of Calliphoridae (Diptera) recently introduced in Brazil. Rev Bras Genet 4: 619-638.

Becker HJ 1976. Mitotic recombinants. In N Ashburner, The Genetics and Biology of Drosophila, Academic Press, New York, p.1020-1084.

Bedo DG 1991. Cytological characterization of heterochromatin in meiotic and mitotic chromosomes of the Old World screwworm fly, Chrysomya bezziana (Diptera: Calliphoridae). Genome 34: 631637.

Bedo DG 1992. Polytene chromosomes of the Old World screwworm fly (Chrysomya bezziana) and its evolutionary relationships with Lucilia cuprina and Cochliomya hominivorax (Diptera: Calliphoridae). Genome 35: 294-303.
Boyes JW 1967. The cytology of muscoid flies. In JW Wright, R Pal (eds), Genetics of Insect Vectors of Disease, WHO Elsevier Publ. Co., Amsterdam, p. 371-384.

Boyes JW, Shewell GE 1975. Cytotaxonomy of Calliphoridae (Diptera). Genetica 45: 435-488.

Boyes JW, Van Brink JM 1965. Chromosomes of calyptrate Diptera. Can Genet Cytol 7: 537-550.

Boyes JW, Wilkes A 1953. Somatic chromosomes of higher Diptera I. Differentiation of tachinid parasites. Can J Zool 31: 125-165.

Boyes JW, Corey MJ, Paterson HE 1964. Somatic chromosomes of higher Diptera. IX. Karyotypes of some muscid species. Can J Zool 42: 1025-1036.

Comings DE, Riggs AD 1971. Molecular mechanisms of chromosome pairing and function. Nature 233: 48-50.

Foster GG, Whitten MJ, Konovalov C, Bedo DG, Maddern RH, Boon DJ 1980. Cytogenetic studies of Lucilia cuprina dorsalis R.-D. (Diptera: Calliphoridae). Chromosoma 81: 151-168.

Guimarães JH, Prado AP, Buralli GM 1979. Dispersal and distribution of three newly introduced species of Chrysomya Robineau-Desvoidy in Brazil (Diptera, Calliphoridae). Rev Bras Entomol 23: 245-255.

Guimarães JH, Prado AP, Linhares AX 1978. Three newly introduced blowfly species in southern Brazil (Diptera, Calliphoridae). Rev Bras Entomol 22: 53-60.

Greenberg B 1971. Flies and Disease, Vol. 1, Princeton University Press, Princeton.

Greenberg B 1973. Flies and Disease, Vol. 2, Princeton University Press, Princeton.

Hadjiolov AA 1985. The Nucleolus and Ribosome Biogenesis, Springer-Verlag, Vienna.

Hiroyoshi T 1977. Some new mutants and revised linkage maps of the housefly, Musca domestica L. Jpn J Genet 52: 275-288.

Imai HT, Takahata N, Maruyama T, Daniel A, Honda T, Matsuda Y, Motiwari K 1988. Theoretical bases for karyotype evolution. II. The fusion burst in man and mouse. Jpn J Genet 63: 313-342.

James MT 1970. Family Calliphoridae. In A Catalogue of the Diptera of the Americas South of the United States, Museu de Zoologia da Universidade de São Paulo, São Paulo, p. 1-28.

Keneuke W 1924. Über die spermatogenese eineger Dipteren. Z Zel Gewebelehre 1: 357-412.

Laurence BR 1981. Geographical expansion of the range of Chrysomya blow flies. Trans R SocTrop Med Hyg 75: 130-131.

Laurence BR 1986. Old World blow flies in the New World. Parasitol Today 2: 77-79.

Levan A, Fredga K, Sanderg AA 1964. Nomenclature for centromeric position on chromosomes. Hereditas 57: 201-220.

Manjunatha HB, Puttaraju HP 1997. Association of chromosomes during spermatogenesis in the uzi fly, Exorista sorbillans (Diptera: Tachinidae). Cytobios 89: 81-89.

Mariluis JC 1980. Presencia del género Chrysomya Robineau-Desvoidy, 1830 em la region Neotropical 
(Calliphoridae, Chrysomyiinae, Chrysomyiini). Rev Soc Ent Argentina 39: 126-130.

Melander Y 1963. Chromatid tension and fragmentation during the development of Calliphora erytrocephala Meig (Diptera). Hereditas 49: 91-106.

Metz CA 1916. Chromosome studies on the Diptera. II. The paired association of chromosomes in the Diptera and its significance. J Exptl Zool 21: 213-279.

Metz CA 1922. Association of homologous chromosomes in tetraploid cells of Diptera. Biol Bull 43: 369-373.

Parise PP, Avancini RMP, Recco-Pimentel SM 1996. Karyotypic characterization of Muscina stabulans (Fallen) (Diptera: Muscidae) using conventional staining, silver staining and C-banding. Caryologia 49: 13-20.

Prado AP, Guimarães JH 1982. Estado atual da dispersão e distribuição das espécies do gênero Chrysomya R. -D. na região neotropical (Diptera, Calliphoridae). Rev Bras Entomol 26: 225-231.

Stevens NM 1908. A study of the germ cells of certain Diptera, with reference to the heterochromosomes and phenomena of synapsis. J Exptl Zool 5: 359-374.

Sturtevant AH, Novitski E 1941. The homologies of the chromosome elements in the genus Drosophila. Genetics 26: 517-541.

Sumner AT 1972. A simple technique for demonstrating centromeric heterochromatin. Exp Cell Res 75: 304-306.
Üllerich FH 1961. Geschlechtsbestimmung bei der Fliege Phormia regina. Naturwissenschaften 48: 559-560.

Üllerich FH 1963. Geschleschtschromosomen und Geschlechtsbestimmung bei einigen (Calliphoridae, Diptera). Chromosoma 14: 45-110.

Üllerich FH 1971. Sex-linkage and sex determination in a monogenic blowfly. Nature 58: 626-631.

Üllerich FH 1973. Die genetiche Grundlage der Monogenie bei der Schmeibfliege Chysomya rufifacies (Calliphoridae, Diptera). Mol Gen Genet 125: 157-172.

Üllerich FH 1976. Chromosomenverhältnisse, konstitutives hetrochromatin und geschlechtsbestimmung bei einigen Arten der Gattung Chrysomya (Calliphoridae, Diptera). Chromosoma 58: 113-136.

Viegas-Pequignot E 1992. In situ hybridization to chromosomes with biotinylated probes. In D Willman, In Situ Hybridization: a Practical Approach, IRL Press, Oxford, p. 137-158.

Zumpt F 1956. Calliphoridae (Diptera Cyclorrhapha). Part I: Calliphorini and Chrysomyiini, Explor Parc Nat Albert, Miss de Witte.

Zumpt F 1965. Myiasis in Man and Animals in the Old World, Butterworths, London, p. 267.

Zumpt F 1972. Notes on Diptera (Sarcophagidae, Calliphoridae) from the Ethiopian geographical region. Z Angew Zool 59: 439-445 